\section{A computer program for confounded factorial designs}

\section{JAMAL ABEDI \\ University of Califormia, Los Angeles, Califomia 90024}

The analysis of variance has greater power when applied to a randomized block design in which the block effect is significant compared with a completely randomized design. However, finding a group of homogeneous subjects to form the blocks is a difficult task because, as Kirk keenly pointed out, "Subject heterogeneity is the rule rather than the exception in behavioral research" (1968, p. 246).

By using littermates, matched subjects, or, in special cases, repeated measures on the same subjects, one can obtain within-block homogeneity. There are, however, limitations to such procedures, especially when either the number of factors or the number of levels of the factors increases.

The use of split-plot designs helps the researcher to reduce the number of treatment combinations. For instance, in a 2 by 2 by 2 randomized block factorial design, a total of eight treatment combinations are needed within each block, whereas, in a 2 by 2 by 2 split-plot factorial with one between-subjects factor, only four treatment combinations are required. However, in a split-plot design, a complete confounding occurs between one or more treatment effects and the block effects. For example, in a 2 by 2 by 2 split-plot design with the $\mathrm{A}$ factor between subjects, the main effect of factor $\mathbf{A}$ is confounded with the block effects.

In confounded factorial designs, such as split-plot designs, the number of treatment combinations within each block can be reduced, but in the former, confounding can be restricted to higher order interactions rather than the main effects. Therefore, if some interactions are believed to be negligible, they can be sacrificed in order to test the main effects and important interactions. Moreover, confounded block designs provide a more flexible and efficient way of reducing the number of observations per subject or the number of subjects within a block than split-plot designs when many factors (e.g., 2 by 2 by 2 by 2 by 2 by 2 by 2 ) are involved.

Different confounded designs have been introduced. Designs might be partially confounded or completely confounded. Each design might have an equal number of

Much of this presentation has relied on Kirk (1968). However, computational procedures on the program are based on Cochran and Cox (1957). Requests for reprints should be sent to Jamal Abedi, Institute for Educational Research, Box 3071 , Teheran, Iran. This work was completed while the author was a visiting scholar at the Graduate School of Education, University of California, Los Angeles. The author wishes to acknowledge the advice and help of Richard J. Shavelson in this project. levels for the factors or unequal numbers of levels. (For detailed information concerning confounded designs, see Cochran \& Cox, 1957; Kirk, 1968; Winer, 1971.)

The computational procedures differ for the different confounded designs. Due to this fact and due to the fact that such designs are not used frequently in educational and psychological research, programs for confounded designs are either not available or are too complicated to use and/or interpret in well-known statistical packages. To help behavioral researchers analyze data from a block design in a simple way and obtain all necessary information for the interpretation of their results, the present program has been prepared.

Description. This program deals with the more widely used confounded designs in which the largest order interaction is completely confounded with the block factor and each factor has two levels. The program can take up to 10 factors and is capable of handling missing data by offering several options.

The program is written in FORTRAN IV for the IBM 360 and 370 and consists of one main line and 24 subprograms. Variable format is used, and the routine is entirely disk resident (Hogge, 1972, Chapter 2). The processing of control cards and error routines has been implemented so that virtually no user action results in an unexplained error. Any number of problem decks can be processed on a given computer run.

Output. The program outputs a summary description, available options, and an analysis of variance summary table, including sources, sums of squares, degrees of freedom, mean squares, $F$ ratios, and probabilities of chance occurrence. It also produces means for blocks by replications and means and variances for all effects (main effects and interactions). The outputs of the analysis of variance summary table and means and variances are optional. The user has the option to obtain the printout of any interaction effect in the table or any sets of means and variances for the main and interaction effects.

Availability. Write to Jamal Abedi, Institute for Educational Research, Box 3071, Teheran, Iran.

\section{REFERENCES}

Cochran, W. G., \& Cox, G. M. Experimental design. New York: Wiley, 1957.

Hogge, J. H. Programming the statistical library. Philadelphia: Auerbach, 1972.

KIRK, R. E. Experimental design: Procedures for the behavioral sciences. Belmont, Calif: Brooks/Cole, 1968.

WINER, B. J. Statistical principles in experimental design. New York: McGraw-Hill, 1971.

(Received for publication June 27, 1979; accepted July $24,1979$. ) 